\title{
POESIA IMPRESSIONISTA NO SIMBOLISMO BRASILEIRO: MARANHÃO SOBRINHO, PEDRO KILKERRY E ERNANI ROSAS
}

\author{
Jairo Nogueira LUNA
}

RESUMO: Neste artigo buscaremos demonstrar como o Simbolismo brasileiro guarda interessantes relações com a escola Impressionista de pintura e de como essas relações impregnaram o nosso Simbolismo de exemplos de poemas com fortes características Impressionistas. Para tal demonstração, nos utilizaremos de poemas de Maranhão Sobrinho, Pedro Kilkerry e Ernani Rosas, uma vez que os três poetas estão entre os que souberam utilizar a questão da percepção da luz para composição dos cenários imagéticos de seus poemas. Deste modo, acreditamos poder apresentar um texto que recupera aspectos um tanto quanto esquecidos do Simbolismo brasileiro.

Palavras-chave: Simbolismo, Impressionismo, Pintura e Poesia.

Abstract: In this article we seek to demonstrate how the Brazilian Symbolism contains interesting relationships with Impressionist school of painting and how these relationships pervade our Symbolism with examples of poems with strong features Impressionists. For this demonstration, we will use the poems of Maranhão Sobrinho, Pedro Kilkerry and Ernani Rosas, once the three poets are among those who could use the issue of the perception of light in composing his poems 
imagistic scenarios. Thus, we believe we can provide a text that recovers somewhat forgotten aspects of Brazilian Symbolism.

Keywords: Symbolism, Impressionism, Painting and Poetry.

A concepção de arte impressionista está por vários aspectos teóricos e pragmáticos ligada ao Simbolismo, embora possamos levantar diferenças específicas aos aspectos técnico-poéticos de uma e de outra. Juan José Balzi faz uma observação fulcral sobre esta questão técnico-poética, destacando as dificuldades entre pintura e poesia, sem com isso querendo afirmar que o Impressionismo seria mais pictórico e o Simbolismo mais literário:

"O Impressionismo, como o Cubismo e outros seus derivados são inovações tecnopictóricas. No entanto, os críticos e historiadores têm, geralmente, uma formação literária. Assim, quando em uma obra de história ou num curso de arte (onde o espaço dedicado à arte moderna e contemporânea é muito reduzida) chega-se ao capítulo que trata destes movimentos, a explicação torna-se sumária e insuficiente. Ou, quando se trata de livros ou ciclos específicos, ela resultará ao leitor ou ao ouvinte complicada demais ou falsamente erudita. É que, na realidade, a tradução de uma linguagem plástico-visual a outra escrita ou falada é mais difícil do que parece." (BALZI, p.8-9)

Poderíamos aqui evocar Lessing, acerca das distinções entre poesia e pintura, mas não creio que seja necessário. Afinal, nosso objetivo central aqui é demonstrar como três poetas nomeadamente simbolistas desenvolveram uma técnica impressionista de composição poética.

Neste sentido, convém destacar a especificidade característica do Impressionismo que é o trabalho com a luz, isto é, como a luz interfere e define nossa apreensão das cores e, mais, como a percepção destas cores pode ser modificada pela nuanças atmosféricas e pela distância que nos encontramos do objeto 
observado ou a posição em que nos encontramos em relação a ele. Desse modo, os pintores impressionistas se dedicaram ao desenvolvimento de uma técnica cromática muito singular no que se refere ao uso das cores e ao modo de pincelá-las, por vezes distorcendo o contorno dos objetos, suas formas, para nos dar a impressão dos efeitos dessa luminosidade na atmosfera. Não é por acaso que o nome do movimento se deve ao quadro "Impressão: Nascer do Sol"(1872) de C. Monet.

Podemos assim enumerar as características do Impressionismo a partir desta questão da luminosidade:

- As tintas devem salientar a forma que os objetos adquirem ao reflexo da luz num momento específico, haja vista que as cores da natureza constantemente, dependendo da hora da incidência da luz do sol;

- Desse modo é também uma pintura instantânea (captação do momento), recorrendo, inclusivamente, à fotografia, como forma de preparação para a pintura;

- Os contornos não são nítidos com destaque para relação mancha/cor;

- as sombras devem ser luminosas e coloridas, tal como é a impressão visual que nos causam.

- os contrastes de luz e sombra devem ser obtidos de acordo com a lei das cores complementares. Assim um amarelo próximo a um violeta produz um efeito mais real do que um claro-escuro.

No caso do Simbolismo, e poderíamos também levantar alguns pintores Simbolistas como Gustave Moreau, Odilon Redon ou Pierre Bonard - não raras vezes inseridos em listas de pintores impressionistas - também existe um aspecto referente à luminosidade, mas conceitualmente são processos distintos. No caso do Impressionismo a visão se sobrepõe aos demais sentidos, de forma que a Sinestesia decorre de uma expansão da visão 
para os outros sentidos, notadamente o tato. Ao passo que no Simbolismo não existe um domínio da visão sobre os demais, mas uma integração eqüitativa quanto possível dos sentidos. Talvez, por isso, a pintura simbolista seja, não raras vezes, considerada impressionista, uma vez que na pintura, a visão naturalmente e conceitualmente se sobrepõe, ficando a distinção nesta arte, muito ligada aos temas pintados do que à técnica.

$\mathrm{Na}$ poesia simbolista os experimentos impressionistas não foram poucos e vamos destacar aqui, no caso do simbolismo brasileiro, três poetas que levaram a cabo o que consideramos boas realizações de técnica impressionista em poesia.

Vamos começar por Pedro Kilkerry e seu poema "O Cetáceo". 0 poeta passou a ser mais conhecido a partir do excelente trabalho de revisão de Augusto, Revisão de Kilkerry (1985). Numa dissertação de mestrado apresentada na UEPB (2009), Paulo Fernando Fonseca Ferreira faz (uma aliteração em ff...?) uma interessante análise dos poemas de Kilkerry e no caso específico do poema "O Cetáceo" começa por dizer:

"Em Cetáceo (ANEXO N), o olhar da liricidade capta na luz evasiva e o instante mais fluido que desmaterializa os objetos em densa plasticidade imagética. A cena só aparentemente se limita à forma parnasiana, uma vez que o soneto e as cadências métrica e acentual do verso (o decassílabo heróico) parecem diluir-se nos sentidos fugidios e nos aspectos precários da descrição (a marinha)." (FERREIRA, p. 97).

Transcrevemos a seguir o soneto:

\section{o Cetáceo}

Fuma. É cobre o zênite. E, chagosos do flanco, Fuga e pó, são corcéis de anca na atropelada. E tesos no horizonte, a muda cavalgada. Coalha bebendo o azul um largo vôo branco. 
Quando e quando esbagoa ao longe uma enfiada De barcos em betume indo as proas de arranco. Perto uma janga embala um marujo no banco Brunindo ao sol brunida a pele atijolada.

Tine em cobre o zênite e o vento arqueja e o oceano Longo enfroca-se a vez e vez e arrufa, Como se a asa que o roce ao côncavo de um pano.

E na verde ironia ondulosa de espelho Úmida raiva iriando a pedraria. Bufa O cetáceo a escorrer da água ou do sol vermelho. (cópia fornecida por Álvaro Kilkerry. In: CAMPOS, 1985).

Destacaremos aqui a questão do trato com a luminosidade no poema e a forma como a percepção desta modifica a escrita do poema por meio do uso de metáforas e metonímias como recurso lingüístico para exploração destas percepções:

Os primeiros dois versos são compostos por dois períodos. Um, simples, de uma só palavra ("Fuma") e outro compreendendo as demais. Ao colocar "Fuma" logo no início do poema, já temos aí uma referência impressionista. Lembremos da fala de Monet: "A única maneira de se dar a impressão da realidade é chegarmos a representar a atmosfera; isto que está entre você e eu (abre e fecha a mão ante os olhos de Manet, como se apanhasse a fumaça do seu cigarro)." (BAZI, p. 27) ${ }^{1}$. De fato, a questão da relação entre a atmosfera e a luz é um dos pontos centrais da técnica impressionista, como já notamos na apresentação de suas características.

O segundo período ("E, chagosos do flanco, Fuga e pó, são corcéis de anca na atropelada.") nos apresenta uma metáfora, ao que me parece, já resultado desta interferência da atmosfera.Os corcéis são imagens percebidas a partir do movimento das nuvens no horizonte, sob a luz do Sol, o efeito rosicler.

E o quarteto se encerra com um terceiro período que

\footnotetext{
${ }^{1}$ As frases e citações de falas de pintores inseridas no livro de Bazi, ao que me parece, são originárias do estudo de John Rewald, História do Impressionismo. Trad. Jefferson Luís Camargo. São Paulo, Martins Fontes, 1991.
} 
compreende os dois versos seguintes: ("E tesos no horizonte, a muda cavalgada. / Coalha bebendo o azul um largo vôo branco."). Continuando na descrição da metáfora anterior, o poeta baiano salienta que o tropel de corcéis encontrar-se em momento de tensão - extáticos ao momento instantâneo de sua percepção - mas num processo sinestésico, salienta que sua cavalgada é "muda", o que é um contra-senso que desvela a metáfora, uma vez que uma cavalgada de corcéis em disparada e tesos seria das mais ruidosas. Esta sinestesia (audição / visão) fornece ao leitor uma pista para a compreensão da metáfora. 0 verso seguinte, considerado por Augusto de Campos um dos mais belos do simbolismo brasileiro, um alexandrino com os hemistíquios $1^{\circ}$ : "Coalha bebendo o azul - acentos na 1. $\underline{\text { a }}$ - resultante de uma união das sílabas co+a -, 3. e 6. e $2 .^{\circ}$ hemistíquio: "um largo vôo branco" - com acentos na 2..$^{\text {a }}$ 4. ${ }^{\text {a } ~}$ e 6. ${ }^{\text {a }}$ sílabas - mantendo-se o hiato de "vôo". De modo que o primeiro só tem acentos em sílabas ímpares e o segundo em pares, como num processo de equilíbrio barroquista. E a união dos dois hemistíquios se faz por um eco: "o + a - zUL // UM", para analogia com o movimento contínuo das nuvens no céu. No eco, o som se propaga, as nuvens por sua vez, se metamorfoseiam continuamente, ao discurso poético de um proteu-poeta.

Observemos três quadros impressionistas que podemos relacionar ao descrito no primeiro quarteto do poema:

O primeiro é o quadro "San Giorgio Maggiore ao anoitecer Claude Monet", notemos o modo como os tons de azul, amarelo e vermelho são apresentados para compor a percepção do horizonte. 


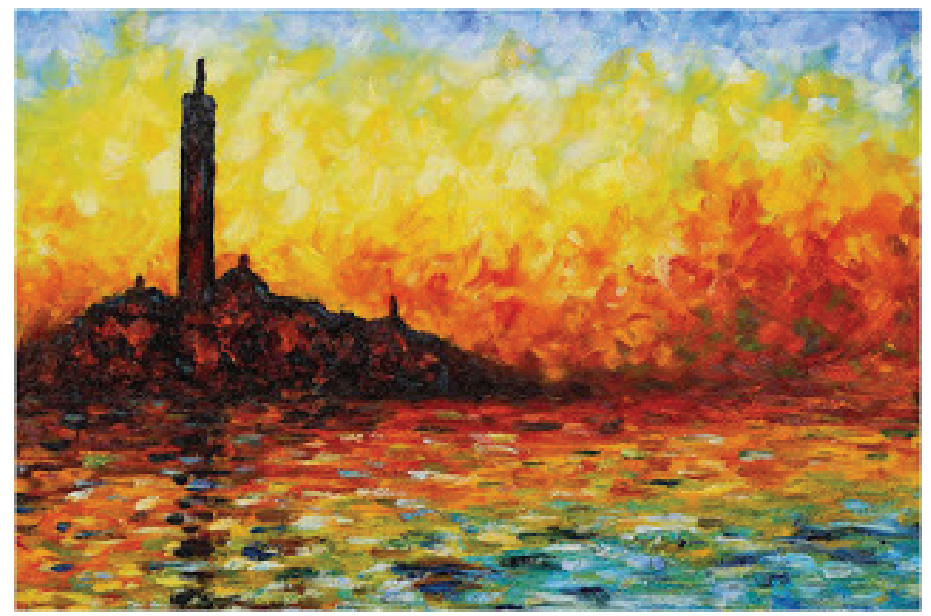

Ou este de André Derain, Ponte em Charing Cross (1906):

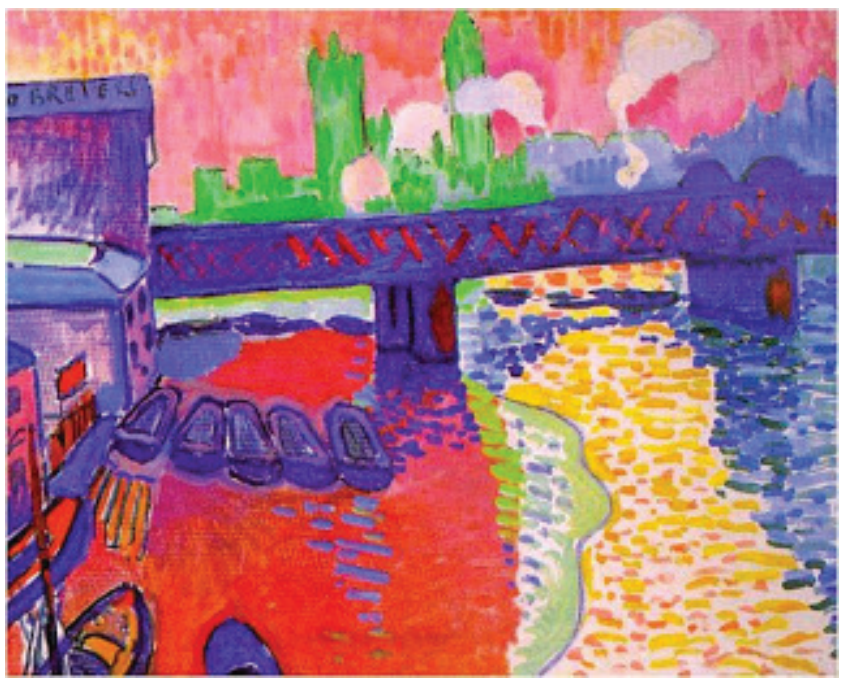

Notemos a intensidade das cores do céu avermelhado e a água do canal, próximo às margens, onde estão os barcos. 0 modo como o tom avermelhado está relacionado à percepção da sombra causada pelas construções sobre o canal.Os contornos difusos e o trabalho com o reflexo do céu e da ponte nas águas. 
Ou este, de Franz Marc, Paisagem com Cavalo (1910), em que notamos o modo como a cor do cavalo é avermelhada, mas a crina de um forte azul. E os tons de azul e vermelho em pequenas porções no cenário do campo amarelo e verde:

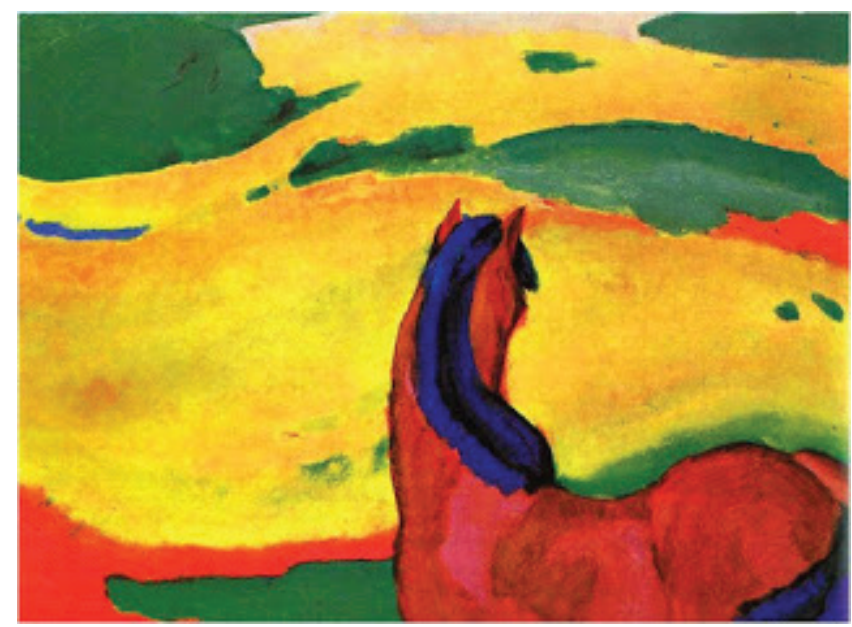

Passemos à análise do segundo quarteto. Que contém dois períodos de dois versos cada. O primeiro ("Quando e quando esbagoa ao longe uma enfiada / De barcos em betume indo as proas de arranco."), nos apresenta o cenário da linha do horizonte mar/céu também pincelada com imagens de barcos. 0 advérbio "ao longe" orienta-nos espacialmente para imaginação da cena proposta. Podemos notar aqui também a questão do uso do negro no Impressionismo. Existe uma tendência a evitá-lo tanto quanto possível, pois por definição, o preto é ausên cia de cor, o que invalidaria a questão da percepção da cor com relação à luminosidade. Assim, o "betume" dos barcos estaria mais para o azul, já citado no último verso do quarteto anterior, talvez num tom mais escuro. 0 verbo "esbagoar", tirar o bago, abrir a vagem, aqui em sentido conotativo, seria a seqüência de barcos aparecendo ao horizonte, em fila, como os grãos numa vagem de feijão, metáfora original. Na expressão 
"proas de arranco", ainda temos por extensão, o verbo, arrancar, contíguo metonimicamente ao sentido de esbagoar.

Notemos o tom com que Monet pinta os barcos no seu famoso quadro “Impressões do Nascer do Sol” (1872):

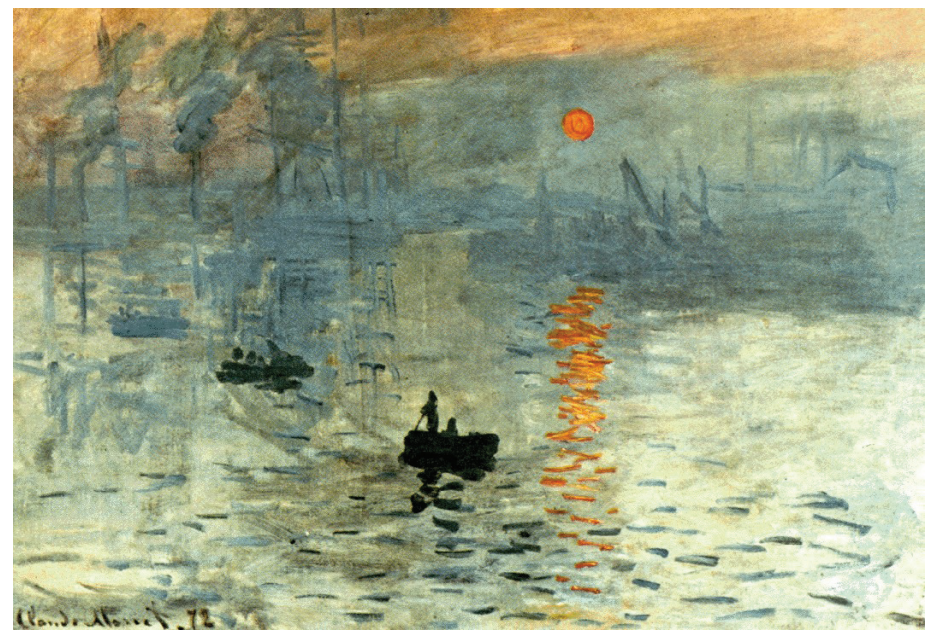

0 tom escuro dos dois pequenos barcos mais próximos e os espectros azulados e difusos dos outros barcos ao que nos parece, numa neblina que vai aos poucos se diluindo ante o Sol vermelho que vai nascendo e já pondo seu reflexo sobre a água.

0 segundo período deste quarteto ("Perto uma janga embala um marujo no banco / Brunindo ao sol brunida a pele atijolada."), apresenta-nos com o advérbio de lugar "Perto" a possibilidade de colocação da cena que vai se descrita para compor o cenário: uma jangada mais próxima do que os distantes barcos ou as nuvens que lembram cavalos no horizonte. Perto o suficiente para olharmos que na jangada está um marujo de pele bronzeada. A personificação da jangada que "embala um marujo no banco" dá um sentido afetivo, singelo, à cena. 0 verbo brunir, no sentido de dar brilho, fazer luzir, enriquece o sentido impressionista da percepção da cena da jangada e do jangadeiro sob a luz do Sol. Apreciemos o tom da pele em “Contos Bárbaros”(1902) de Paul Gauguin: 


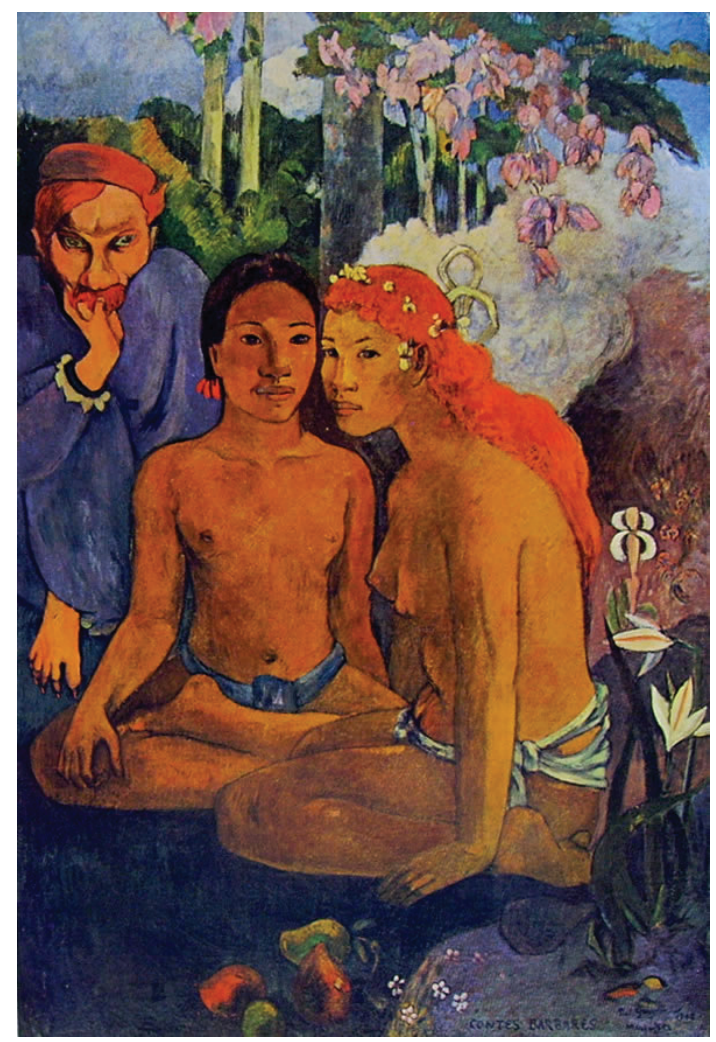

O modo avermelhado como ele apresenta o tom da pele das duas figuras seminuas, algo indianas. 0 sombreamento que ele dá para captação dos efeitos de luz.

No poema de Kilkerry, a expressão "pele atijolada" é uma adjetivação metonímica, uma vez que a cor do tijolo - barro vermelho - é usada para se referir à cor da pele do marujo brilhando sob a luz do Sol.

No primeiro terceto temos um só período. Começa com o verbo "tinir", que é relativo à produzir som no metal ou vidro. No caso, metal, pois logo a seguir fala na cor do cobre. Temos uma sinestesia, audição / visão. 0 zênite reforça a idéia de percepção da luz Solar com intensidade, uma vez que a cor do cobre - avermelhada, cor de fogo - associa-se à idéia de um ponto mais central e elevado do Sol 
naquele momento. Assim, com relação ao quarteto inicial já temos um horário diferente, já que no primeiro o rosicler é que dominava a percepção que o poeta tem das nuvens e dos barcos no horizonte, portanto, o amanhecer. E agora, o Sol a pino.

Neste terceto, três elementos da Natureza se relacionam: o Sol (na sinestesia cobre/tinir - brunir/zênite), o vento que arqueja (personificação e metonímia) e o oceano que enfroca-se (metáfora). 0 vento é personificado em um ser que está esbaforindo, ofegante, devido ao calor do Sol, ao mesmo tempo, esta respiração arquejante é natural de quem tenha dificuldade em respirar naturalmente o ar (vento), assim, nesta personificação, existe também uma metonímia em que o ser respirante é substituído pelo respirado. 0 vento ao enfrocar-se, isto é, fazer frocos (tênues filamentos) que costumeiramente relacionamos à idéia de flocos, é uma metáfora para as espumas das ondas do mar. Uma vez que o oceano LONGO permite ao poeta imaginá-lo na ação de enfrocar-se, cujo resultado imagético são suas ondas. E a ação de arrufar, que tanto pode relacionar-se à idéia de fazer rufo (produzir som), como a de ouriçar ou arrepiar e mais ainda a idéia de zangar-se, que se liga à vela da jangada, côncava pela ação do vento, mas ao mesmo tempo, como alguém que zangado enche as bochechas, portanto, metaforicamente vendo o pano branco da vela. 0 verbo "roçar", no sentido de raspar, tornar áspero, continua a imagem da vela em relação ao vento.

A riqueza de figuras deste terceto, a complexa relação que se estabelece entre elas é como se o poeta Pedro Kilkerry concebesse que se na pintura impressionista o tom dominante é o trabalho com as cores de modo a demonstrar, por meio delas, a relação com a luz, na poesia, as cores são dadas pelo uso de figuras, portanto, utilizálas para descrever a forma e o tom dos seres e das coisas seria um recurso impressionista.

A relação cor / figuras é bem discutida na Retórica, na Poética, em diferentes autores, desde Aristóteles e para tanto, basta lembrarmos do parágrafo 2, do cap. XXVI da Arte Poética de Aristóteles: 
"Sendo o poeta um imitador, como o é o pintor ou qualquer outro criador de figuras, perante as coisas será induzido a assumir uma dessas três maneiras de as imitar: como elas eram ou são, como os outros dizem que são ou dizem que parecem ser, ou como deveriam ser."

Por outro lado, a relação cor (visual) com palavras (som, forma) está já fundamentada no Siumbolismo, em Rimbaud (Voyelles), em Baudelaire (Correspondances), em René Ghil e seu quadro de relações sinestésicas.

No último terceto, temos dois períodos - como no segundo quarteto - e o primeiro período ("E na verde ironia ondulosa de espelho / Úmida raiva iriando a pedraria") a complexidade das figuras continua se desenvolvendo ricamente. A relação sonora ironia / iriando que se expande para uma aliteração (ironia - raiva - iriando - pedraria) já instaura uma série de figuras: a verde ironia é o reflexo do céu azul-branco nas águas verdes do mar, ondulosa (esbranquiçada, de enfrocar-se) e a raiva é a força com que se iria, dá brilho, matizam-se as cores. E aqui "pedraria" que é uma transformação metonímica de conteúdo para formulação metafórica, haja vista que pedra e água do mar são elementos bem distintos quanto à dureza e textura, mas por outro lado, a formulação anterior das espumas, fica reforçada se pensarmos em pedras (rochas) contra as quais a água do mar bate mais fortemente. Se ao longe vemos barcos, e perto vemos a jangada (lembremos ainda do adjetivo atijolada), a idéia de colocarmos no cenário pedras contra as quais a água bate não é de modo algum fugir ao texto. E, ainda, se pensarmos que isto é a visão que o poeta tem de um cenário da natureza, cabe nos perguntar, em que posição se coloca o poeta, e deve estar mais para cá da jangada, ou seja, próxima as pedras ou praia.

Observemos, para efeito de comparação, como Renoir na tela $L a$ Grenouillere (1869) pinta a textura da água do calmo lago, como coloca os barcos sobre a água e o jogo de reflexos entre o verde da vegetação e a água. 0 líquido tem sua densidade aumentada numa impressão visual que busca a transcendência do visual para o tátil. 


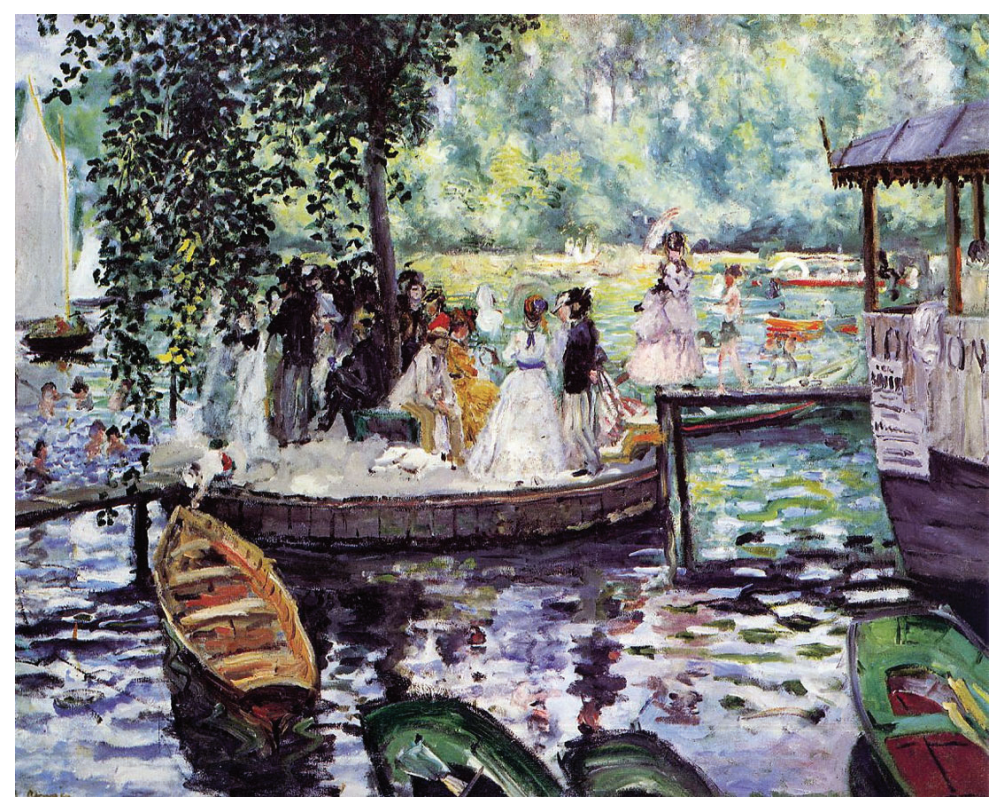

No último período do poema, como uma chave de ouro, temos o aparecimento do ser que dá título ao poema. A baleia, enorme se comparada à frágil jangada, surge das águas, ou aliás, e aí é que se coloca uma nova dimensão perceptiva: a baleia escorre água, no caso de emergir, ou escorre luz no caso de submergir, ou ambas as coisas em ambos os casos. A luz líquida, a água-pedra, enfim uma transformação alquímica dos elementos, a busca da densidade da cor na luz impressionista. 0 verbo no presente do indicativo, "Bufa", retoma sonoramente a primeira palavra do poema por efeito aliterativo: Fuma / Bufa, e o confronto F-B (fricativa surda substituída por oclusiva sonora) é bem o barulho que o enorme animal produz no cenário, ao agitar das águas - como as águas nas pedras - ao respiradouro, ao bater das nadadeiras na superfície maior que o roçar do vento na côncava vela, e ainda, o tom da pele da baleia, expandindo a pele atijolada do marujo na janga.

Enfim, um dos mais ricos poemas simbolistas da literatura brasileira, e ao mesmo tempo, exímio exercício de observação impressionista em versos. 
Outro poema que trataremos de Pedro Kilkerry é "O Verme e a Estrela”. O poema já foi gravado por Adriana Calcanhoto, musicado por Cid Campos, filho de Augusto de Campos. 0 poema que se constrói num interessante jogo sonoro entre as palavras verme e epiderme e numa antinonímia com a palavra luz, assim perfazendo um jogo de sinestesias, uma vez que a luz se percebe pela visão, ao passo que a epiderme é táctil:

"Agora sabes que sou verme. agora sei da tua luz.

se não notei minha epiderme...

é nunca estrela eu te supus.

mas se cantar pudesse um verme, eu cantaria a tua luz".

A percepção de si mesmo, e o reconhecimento da condição inferior diante da suposta estrela coloca o eu-lírico num embate contínuo como uma arrastar de verme pela superfície terrena em busca do entendimento da enorme distância que o separa da luz estelar. Evidentemente, tal condição, metáfora da inatingibilidade de algum desejo ou amor idealizado se compraz na hipérbole desta enorme distância e diferença. A exígua dimensão do verme e a imensa distância, luminosidade e tamanho de uma estrela. Assim, mais do que simbolista, este poema, guarda em sua estrutura o jogo das impressões sensoriais, o jogo da luz que atinge um verme, que ao que nos parece, não dotado de visão, como é característico dos vermes, mas com epiderme sensível o suficiente para percepção do calor luminoso.

\footnotetext{
"Olho examino-me a epiderme olho e não vejo a tua luz vamos que sou talvez um verme estrela nunca eu te supus olho examino-me a epiderme Ceguei! ceguei da tua luz".
} 
Tratemos agora de um poema de Ernani Rosas (1886-1954), poeta de quem Augusto de Campos, escreve num artigo, em que demonstra as influências e as relações de recriação com a poesia de Mário de Sá-Carneiro e de Eugênio de Castro, além de sua admiração por Mallarmé:

\begin{abstract}
"Se a linguagem de Ernani Rosa tem a sua individualidade até certo ponto afetada pela porosidade que oferece a outros estilos -e nisso ele difere de Pedro Kilkerry, dono de um idioleto mais pronunciado -, essa circunstância não chega a tolher-lhe a invenção, patente na reelaboração crítica eseletiva queleva o poeta a soluções extraordinárias e a configurações lingüísticas inteiramente estranhas à tradição e ao contexto brasileiros." (CAMPOS, 1990).
\end{abstract}

O poema escolhido para trabalho neste artigo é "Salomé", um soneto que trata de figura carismática, simbólica e cara ao Simbolismo em geral ${ }^{2}$. Se o primeiro verso começa com uma metáfora até certo ponto previsível, a de colher semelhança entre a dança de Salomé e a de uma mariposa ("Ó Bailarina, oh! mariposa inquieta!"), logo nos versos seguintes o poeta desfila um conjunto original de metáforas: as cores das gemas e a cor do entardecer ("Aljofrada da gema de uma tarde."), entre Salomé e um barco ágil ("És nume, Salomé, ágil goleta..."), e ainda, uma sinestesia surpreendente extraída da relação entre o incenso que volteia no ar e a cor do ouro derretido ("dentre o incenso da sombra que oura e arde..."), recuperando a imagem do Sol ao entardecer ante a fumaça do incenso.

$\mathrm{Na}$ segunda estrofe, continuando com uma base imagética estelar, agora citando o cometa e a Lua. No que se refere ao cometa, estrela-errante, se num primeiro momento pode parecer uma

\footnotetext{
${ }^{2}$ Sobre a figura de Salomé no Simbolismo brasileiro, veja meu texto "Starlets do Simbolismo Brasileiro", publicado no livro Monografias de Literatura, Teatro, Comunicação e Semiótica. São Paulo, Epsilon Volantis, 1999. Sobre a figura de Salomé no Sensacionismo europeu, indicamos o estudo de Álvaro Cardoso Gomes, "Salomé, Starlet Simbolista (Eugênio de Castro", publicado no seu livro O Poético: Magia e Iluminação. São Paulo, Perspectiva, 1989.
} 
metáfora fácil para Salomé, a forma como Rosas escreve o verso é que recupera para a linguagem a capacidade criativa da mesma, desvelando do óbvio, a novidade: "Espectro errante de um cometa absorto / após a bacanal 'saturniana'!...". Deste modo, as expressões "espectro errante" e "bacanal saturniana" se dinamizam numa metaforização dos movimentos da dança de Salomé. No verso seguinte, a imagem da flor perfumada (nardos) e sua proximidade com o cenário do Mar-morto, de modo que a dança de Salomé seja também um signo de morte.

0 último verso deste segundo quarteto, apresenta a Lua como "irial" e "sibariana". Irial por ser a percepção das cores dos véus da dança de Salomé, sibariana, pela luxúria e hedonismo da dança sensual.

0 primeiro terceto, o poeta redimensiona a imagem da dança de Salomé, para uma nova concepção, a transformação de seus véus e seus movimentos metaforizados na imagem estelar de um céu noturno claro, em que a névoa estelar da Via-Láctea é um dos véus de Salomé caindo sobre a Terra:

\footnotetext{
"Chovem do céu os raios da nova aurora sobre seu corpo d'âmbar colmado da via Láctea que su'alma olora..."
}

Metáfora hiperbólica, original, criativa, sinestésica (raios visão; corpo - tato; âmbar, olor - olfato). E criando uma sugestão de esperança ("raios da nova aurora") em razão da beleza, como se as próprias palavras do poema dançassem sobre os significados e as imagens, a cada verso, palavra, rima ou sílaba.

0 último terceto, a imagem estelar volta-se para o significado da dança de Salomé, para a morte que causa - do profeta João Batista - mas ao mesmo tempo, o poeta atenta para a beleza da dança, para a sensualidade fulgurante, como se demonstrasse que o "Mal", que aparece no último verso entre aspas, se relativiza diante do prazer estético da visão e da audição da música e da dança: 
"Numa auréola de Luz e alegoria

Esvaindo-Te em Sonho musicado, para a glória do "Mal" que a irradia..."

A aproximação sonora entre "auréola" e "alegoria" abrindo o terceto e a expressão "Sonho musicado", que propõe, ao meu ver, uma nova possibilidade de sinestesia, porém, não entre os sentidos usuais, mas entre a audição (musicado) e o inconsciente (o sonho), ou seja, ouvir a música em sonho, findando com a irradiação (visão) do "Mal" relativizado.

Podemos, agora, ler o poema observando o quadro de Gustave Moreau, Salomé, chamada de tatuada (1871):

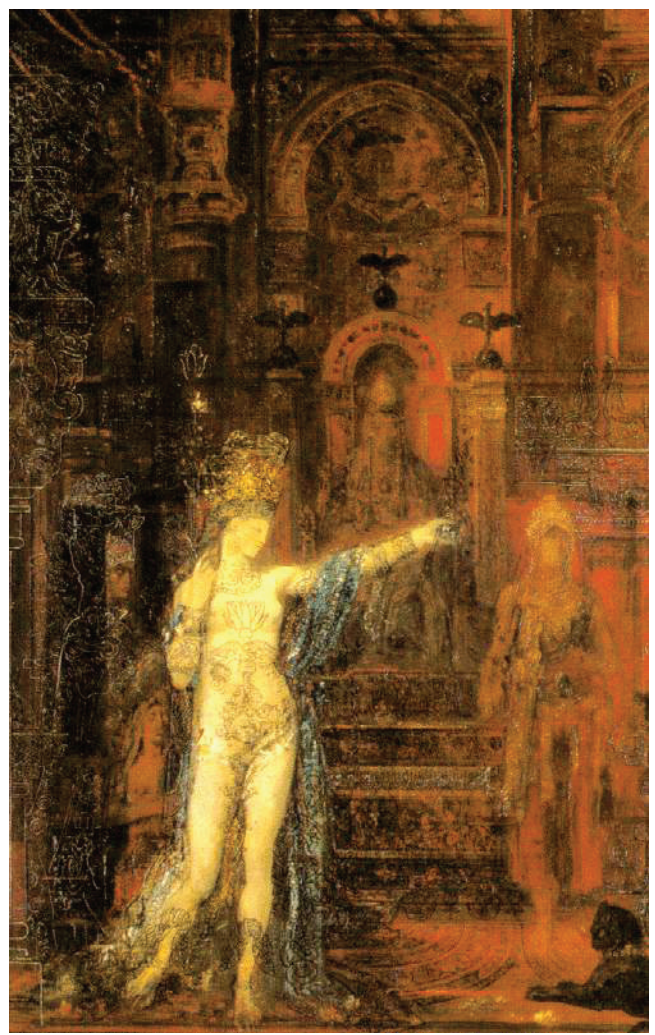


Observemos no quadro de Moreau, o véu azul caindo-lhe dos braços, a sutileza transparente dos tecidos, a luminosidade que cai sobre a figura da dançarina enquanto ao redor, as demais figuras encontram-se numa penumbra avermelhada, como o entardecer, destacando-se ao fundo, mas em posição central no quadro, a figura atenta e atônita de Herodes. É muito provável que Ernani Rosas não tivesse visto o quadro, uma vez que sendo um poeta pobre, de parcos recursos, morrendo esquecido no Rio de Janeiro, vindo de Florianópolis, além de sofrer discriminação por ser gago e homossexual, não se tem notícia de que tivesse ido ao estrangeiro, onde poderia ver o quadro de Moreau, nem que tivesse alguma reprodução acessível. Mas, o modo como Rosas apresenta sua Salomé, é um bom exemplo da utilização dos recursos impressionistas relativos à valorização do jogo de luz, das impressões visuais sobre os sentidos e das correlações de sinestesia que isto pode provocar.

Mas poucos poetas simbolistas foram tão impressionistas quanto Maranhão Sobrinho (1879-1915). Poeta de versificação rica, original e extraordinária, utilizando imagens e metáforas como quem pinta quadros, Maranhão Sobrinho, porém, como a maioria de nossos poetas simbolistas, caiu no esquecimento, sendo lembrado eventualmente em parcos estudos e artigos.

Destacaremos dois sonetos deste poeta singular. 0 primeiro é "Interlunar", poema muitas vezes lembrado pela sonoridade singular de suas rimas (-ânio, -ênio, -ínio, -ônio, únio). 0 poema constrói uma imagem do pôr-do-Sol, tema caro aos simbolistas e aos impressionistas, por motivos próximos, mas diversos. O Sol, metaforizado em "hoplita messênio", "recolhido essênio", vencido se esconde num horizonte que é um "planalto de urânio". No segundo quarteto, temos a sugestão da tumba de Mallarmé, atrás da qual os últimos raios de Sol se escondem:

\footnotetext{
"Veloz como um corcel, voando num mito hircânio, tremente, esvai-se a luz no leve oxigênio da tarde, que me evoca os olhos de Estefânio Mallarmé, sob a unção da tristeza e do gênio!”
} 
A riqueza das sonoridades em Maranhão Sobrinho pode ser bem representada pelo primeiro verso deste quarteto: VELOZ ComO um-m-m-m CorcEL Voan-n-n-do num-m-m-m mIto hIrc-ân-n-n-io. As sensações sinestésicas trabalhadas com detalhe, a sensação da velocidade do vôo de um corcel - o que nos lembra um verso de Pedro Kilkerry em "O Cetáceo" - a Luz que se esvai ao entardecer na atmofesra (oxigênio) e os olhos de Mallarmé, porém, fechados, uma vez que está morto.

Nos tercetos a Noite se sobrepõe ao cenário, uma vez que o Sol, vencido, se esconde. É domínio das sombras, porém, pétreas (Ônix), duras, convincentes sobre toda a imagem apresentada. 0 último brilho do rosicler ao horizonte - o famoso crepusculismo simbolista - é a testemunha de um assassinato, a da luz, que por sua vez, é a metáfora da poesia de Mallarmé.

As "torres medievais" são impressões da visão do túmulo do poeta francês. Assim, neste soneto, Maranhão Sobrinho, presta homenagem ao seu poeta preferido, tendo se notabilizado pela constante referência que faz à obra do simbolista francês.

Em outro poema, "Equatorial", também um soneto, o poeta Maranhão Sobrinho nos apresenta a partir de um cenário inusual na poesia, um lodo visguento ("Sobre o lodo escorrega o musgo. A renda") e os insetos e vermes que por lá vivem ("E na lama, que a lesma azul, meandra de rugas" / .../ "arrastam-se pulsando as moles sanguessugas"), um conjunto de versos que fazem por trabalhar com maestria a sonoridade, as sinestesias e as metáforas, quase como quem pintasse o lago impressionista onde brotam as flores aquáticas, porém, num tom mais lúgubre e escuro.

A tropicalidade evocada no poema é justamente o cenário oposto daquela "multidão de insetos" idealizada no poema de Bilac ("Pátria" - "Não verás país nenhum como este”...), uma vez que aqui, em Maranhão Sobrinho é o conjunto de imagens dum cenário algo asqueroso, mas rico em vida, em que o que para nós é de sentido de nojo, para a vida é berço de criação e transformação: 
"Sobre o lodo escorrega o musgo a renda. Em viços soberbos, o esplendor das aquáticas sarças beira o líquido espelho em que, de espantadiços olhos, banham-se, ao sol, as branquicentas garças."

Comparemos, por exemplo, o poema "Tropical" com dois quadros de Claude Monet, "Estudo da Água" e "Nenúfares". No primeiro, o movimento ríspido, as cores escuras dão nos a impressão duma água barrenta, lodosa, sem reflexo; ao passo que o segundo, vivo em cores, quase que translúcido, nos remete a um cenário de vida.

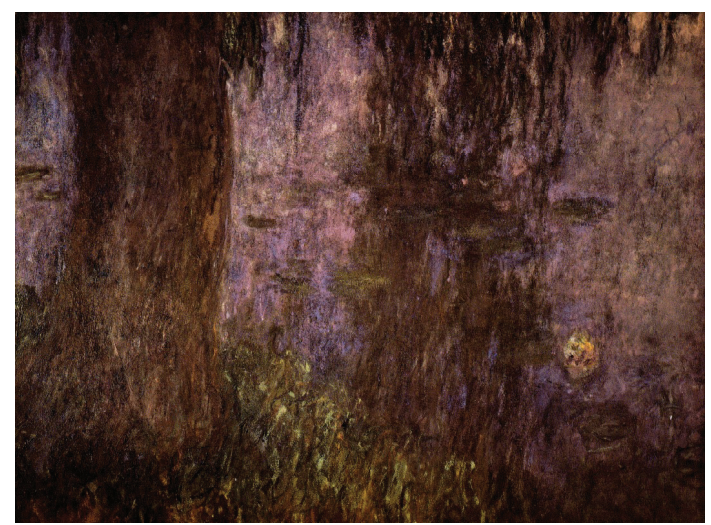

Claude Monet, Estudo da Água

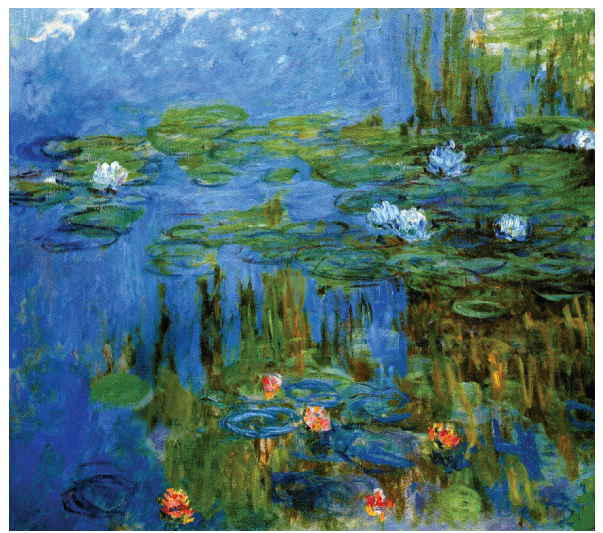

Claude Monet, Nenúfares. 
Porém, em ambos, o que se sobressai é a busca pela compreensão da luz como determinante da imagem e, portanto, da pintura. Daí o Impressionismo ser considerado a escola de pintura que trabalha a forma de como a luz impressiona nossa percepção visual e estabelece os limites de nossa capacidade visual. Neste sentido, é uma técnica que busca a recuperação de nossa capacidade de olhar para além dos limites da convencionalidade cotidiana. Em Maranhão Sobrinho, por seu turno, a par de sua influência mallarmaica, existe uma proposta análoga, só que o poeta - como é característico da poesia, lembramos Lessing - o faz pelo uso da palavra, pelas sinestesias, pelas metáforas e pela exploração da sonoridade com a intenção última de redescobrirmos a capacidade imagética da imaginação.

Assim, ao fim e ao cabo deste artigo, espero ter demonstrado como o Simbolismo brasileiro guarda interessantes e criativos exemplos da proximidade com o Impressionismo. E se o Impressionismo, costuma ser referenciado como escola de pintura em primeiro plano, não é de se menosprezas os modos como se utilizou da técnica impressionista na composição de poemas no Simbolismo brasileiro.

\section{Referências bibliográficas}

ARISTÓTELES. Arte Retórica e Arte Poética. Rio de Janeiro, Ediouro, 2001.

BALZI, Juan José. O Impressionismo. São Paulo, Ática, série Princípios, vol. 225, 1992.

CAMPOS, Augusto de. Revisão de Pedro Kilkerry. São Paulo, Brasiliense, 1985. 
CAMPOS, Augusto de. “O Enigma Ernani Rosas”. São Paulo, Revista da USP, Set./out./nov., 1990, p. 157-172.

FERREIRA, Paulo Fernando Fonseca. O Verbo Encarnado na Alma Cósmica: A Poesia de Pedro Kilkerry. Dissertação de Mestrado, orientador: Prof. Dr. Milton Marques Júnior. João Pessoa, UFPB, 2009.

LESSING, Gotthold Ephraim. Laocoonte. São Paulo, Iluminuras, 1999.

REWALD, John. História do Impressionismo. São Paulo, Martins Fontes, 1991.

ROSAS, Ernani. Poesias. Em: Orfeu Spam Apostilas. Disponível em: $\quad$ http://www.jayrus.art.br/Apostilas/ LiteraturaBrasileira/Simbolismo/Ernani Rosas.htm

SOBRINHO, Maranhão. Poesias. Em: Orfeu Spam Apostilas. Disponível em: http://www.orfeuspam.com.br/Apostilas/ LiteraturaBrasileira/Simbolismo/MARANHAO_SOBRINHO. $\underline{\mathrm{htm}}$ 